\title{
DA CADEIA SIGNIFICANTE À CONSTELAÇÃO DE LETRAS: OS SIGNOS DO GOZO*
}

Márcia Rosa

Psicóloga, psicanalista, membro da Escola Brasileira de Psicanálise e da Associação Mundial de Psicanálise; doutora em Literatura Comparada (UFMG); pósdoutorado em Teoria Psicanalítica (UFRJ) sob a orientação da profa. dra. Tania Coelho dos Santos. Professora recém-doutora no Departamento de Psicologia da UFMG (Fapemig).

RESUMO: O funcionamento constelar, que começa com Mallarmé (1897) e vigora principalmente na primeira metade do século XX nas letras e nas artes, declina no início dos anos 1970, momento no qual entra em consideração no campo da psicanálise através do texto “Lituraterra” (1971), de Jacques Lacan. Essa entrada, a partir da qual a letra torna-se signo de gozo, é possibilitada pelo declínio do estruturalismo e da linearidade da linguística saussuriana e, de algum modo, abre as trilhas para uma escrita borromeana.

Palavras-chave: Constelar, letras, artes, psicanálise.

ABSTRACT: From the significant chain to the constellation of letters: the signs of jouissance. The constellation functioning, that starts with Mallarmé (1897) and invigorates mainly in the first half of the twentieth century in the field of Letters and Arts, declines at the beginning of the seventies, moment in which it enters into consideration in the field of Psychoanalysis in the text "Lituraterra" (1971). This entrance, from which the letter becomes a sign of jouissance, is made possible by the decline of structuralism and of the linearity of the saussurian linguistics and, in some way, it opens the trails to the borromean writing.

Keywords: Constelar, letters, arts, psychoanalysis.

\footnotetext{
*Este texto foi originalmente um capítulo da tese de doutorado intitulada "Fernando Pessoa e Jacques Lacan: constelações, letra e livro", defendida no Programa de Pós-Graduação em Letras: Estudos Literários (UFMG), em 2005, sob a orientação da profa. dra. Maria Ester Maciel de Oliveira Borges.
} 
A escritura constelar, que entra no campo discursivo da psicanálise no início dos anos 1970, está em cena no campo das artes (literárias e plásticas) desde o final do século XIX. O declínio do movimento estruturalista e da influência da linguística saussuriana com a sua linearidade significante, bem como o encontro com a língua japonesa, trarão algumas questões decorrentes do modo de agrupamento constelar para o texto e a clínica lacanianos; assim, o constelar contribuirá para uma nova concepção do inconsciente, como memória de gozo, bem como para uma nova modalidade de escrita, borromeana.

\section{PLANETAS QUE FALAM}

Desde antes do surgimento da ciência moderna, a ordem do real apresenta-se naquilo que retorna sempre ao mesmo lugar. Assim, certa estrela poderá ser encontrada em certa hora da noite sobre certo meridiano; ela retornará, estará sempre lá; ela, sempre a mesma. Em vista disso, Lacan menciona a distinção existente entre a dimensão do real e aquela da verdade e indica que as estrelas são reais na medida em que "não há nelas, em princípio, absolutamente nada que seja da ordem de uma alteridade para com elas próprias, são pura e simplesmente o que são” (LACAN, 1954-1955/1985, p.300).

Por que será que os planetas não falam? Apesar de aparentemente absurda, essa questão atraiu a atenção de Lacan. A partir dela, Lacan observou que Newton reduzira o mundo dos planetas a "uma linguagem justa, bem feita, sintática, ultra-simples” (idem). A partir daí, ele encontrou a configuração que tanto apavorava Pascal, ou seja, a do silêncio eterno dos espaços infinitos. Reduzidos a uma fórmula definitiva, os planetas perderam a fala. Todavia, se a possibilidade de reduzir os seres ao silêncio permite fazer ciência, a meta da psicanálise, bem como da literatura, não seria, certamente, a de chegar a um campo unificado, transformando os homens em luas. Trata-se, pelo contrário, de devolver-lhes a palavra. Quanto a isso, o psicanalista adverte não ser necessário cair no misticismo, a coisa ficaria demonstrada a partir do momento em que eles começassem a nos mentir (idem).

Se o real é pura e simplesmente o que é, se ele retorna, silenciosamente, sempre ao mesmo lugar, em contrapartida, o modo como os pontos luminosos no espaço celeste são agrupados em constelações (e começam a tagarelar!) mostra a "maneira pela qual o simbólico agarra”, e começa a ter um papel (idem). Assim, as constelações são, de saída, e fundamentalmente, um dos modos de subjetivar o real. Nesta acepção, Lacan se vale do termo em vários momentos, fazendo-o incidir em contextos diversos. Surgem assim constelações familiares, parentais, femininas, internas e externas, do real, simbólico e imaginário, de entrada e saída da análise etc., sem que se desconheça a importância do sujeito, uma vez que os pontos estelares — desconhecidos uns dos outros — não se agrupariam por si sós. 
Nos anos 1950, a noção de constelação surge (" e por que não? no sentido em que dela falam os astrólogos ”, diz Lacan (1953/1980, p.55-57) no contexto de uma análise estruturalista dos mitos, sejam eles os que presidem a neurose do Homem dos Ratos, a neurose do Pequeno Hans ou aqueles que organizam a trilogia dos Coûfontaine, de Paul Claudel. Trata-se aí da "coerência significante que existe entre a primeira constelação [isto é, a primeira geração] e aquela que se segue" (LACAN, 1960-1961/1992, p.310). Fica indicado que a constelação significante opera por meio de um sistema de transformações, isto é, um movimento de rotação que cobre o significado, em cada momento, de um modo distinto e que, ao mesmo tempo, exerce uma ação transformadora. Assim, da constelação dos significantes, tal como surge nas associações, o psicanalista extrai sua certeza. Nos primeiros usos do termo, nota-se uma sinonímia entre o significante e a letra, bem como o fato de a “constelação de Vorstellungen” (LACAN, 1959-1960/1988, p.77) regular as associações dos pensamentos inconscientes.

Em 1958, Lacan se refere à “constelação de insígnias que constituem para o sujeito seu Ideal do Eu” (LACAN, 1958/1998, p.686), traços significantes, marcas da resposta do Outro que transformam o grito em apelo. Por que, neste momento, ele usa o termo constelação e não cadeia, por que se refere a insígnias e não a significantes?, indaga Jacques Alain Miller, em um curso intitulado Ce qui fait insigne. No seu entender, Lacan introduz aí uma "oposição conceitual” entre a cadeia e a constelação, oposição que ele não desenvolve, deixando-nos, portanto, algo a fazer (MILLER, 1987/1999, p.139-154).

\section{Uma constelação de insignias}

Tratadas pela psicanálise como significantes imaginários, as insígnias designam as marcas distintivas de um sujeito, os seus emblemas, os seus brasões. Localizadas naquele ponto no qual uma imagem tem valor simbólico, Freud as abordou com a noção de Ideal do Eu e Lacan as formalizou com as iniciais I(A), escritas com letras maiúsculas para marcar a dimensão simbólica em jogo nessas imagens, e com a notação 'A' para designar que o sujeito toma esses traços emprestados ao Outro (Autre). ${ }^{1}$

Consoante Miller (1987/1999), com a expressão “constelação de insígnias” Lacan indica que esses significantes emblemáticos introduzem um modo de identificação diferente daquele que é o agrupamento dos traços em cadeia significante. No agrupamento em cadeia prevalece a ordem da representação e o significante representa o sujeito perante um outro significante $(\mathrm{S} 1 \rightarrow \mathrm{S} 2)$. À guisa de exemplo, diríamos que aí o sujeito surge dividido entre dois significantes, tal

\footnotetext{
${ }^{1}$ A partir do final dos anos 1960, à medida que a inexistência do Outro vai sendo enfatizada, as 'insígnias' passam a ser abordadas na álgebra lacaniana sob o termo "Significante Mestre", e escritas com a notação S1.
} 
como a Rainha do conto de Edgar Allan Poe, "A carta roubada”, está dividida (\$) entre aquilo que a carta (S1) suscita nela e a sua relação ao Rei (S2). Todavia, essas marcas distintivas podem também “[...] captar a identificação ali aonde ela não é uma representação, ali aonde o sujeito se toma por um só (un tout seul). A ideia da constelação de insígnias implica justamente isto” (idem, p.149-150). Assim com a insígnia, o sujeito se toma pelo Um, por uma substância, uma entidade. Nesse caso, a carta (letter) recebida pela Rainha apresentaria algo que excederia a representação, mostraria um excesso e evocaria a dimensão de algo clandestino (letter/litter), situação na qual seria legível como memória de gozo.

Portanto, ao apresentar o Ideal do Eu como uma constelação de insígnias, Lacan deixa indicado que os traços que o sujeito toma emprestados ao Outro podem funcionar como significantes civilizadores que, além de representálo, fazem com que seja reconhecido pelo Outro (idem), mas podem também se soltar do sistema significante, serem extraídos da cadeia significante, e se transformarem em insígnias que existem tout seul, - absolutamente sós, como tão bem traduziu Branco (2000). Redutores do Outro, esses significantes soltos (desencadeados, portanto!) operam fora do sistema simbólico na sua face representativa e comunicativa, fundada na lógica simbólica. Neste sentido, eles operam como letra.

Escrevendo, sinteticamente, teríamos:

$$
\begin{aligned}
\text { Ideal do Eu } & \longleftrightarrow \text { Insígnias } \\
\mathrm{I}(\mathrm{A}) & \longleftrightarrow \text { I }(1,1,1,1, \ldots) \\
\text { Singular } & \longleftrightarrow \text { Plural } \\
\text { Significante } & \longleftrightarrow \text { Letra } \\
\text { S1 } \rightarrow \text { S2 } & \longleftrightarrow \text { S1//S2 } \\
\text { Cadeia } & \longleftrightarrow \text { Constelação }
\end{aligned}
$$

Um movimento terá sido feito, e ele nos conduz dos Ideais do Outro, I(A), tomados na sua face significante, aos traços tomados Um a Um, I $(1,1,1,1, \ldots)$, movimento no qual a identificação será levada ao ponto limite onde falta significante, S(de A barrado). Neste movimento, a própria hegemonia do simbólico, fundada no binarismo significante, um dos fundamentos do estruturalismo, é colocada em questão. O império do significante transforma-se em um império de semblantes e ele traz de volta os signos que, ao ressurgirem, portam em seu bojo a contingência do múltiplo.

É nesse sentido que o termo “constelação” ressurge no texto “Lituraterra” (1971), e leva a uma mudança na definição do constelar que não será sem consequência sobre o sujeito e que, em certo sentido, inaugura o último momento do ensino de Lacan, no qual a temática do constelar ressurge sob a noção de enxame. 


\section{"Lituraterra"}

Lacan mostra em "Lituraterra” que, devido às particularidades de sua língua, o sujeito japonês "está dividido, como por toda a parte, pela linguagem, mas um de seus registros pode se satisfazer pela referência à escritura e o outro pela palavra" (LACAN, 1971/2003, p.24). Temos, neste sentido, não um sujeito dividido entre o dito e o dizer, entre o enunciado e a enunciação, mas um sujeito que se satisfaz oscilando entre o escrito e o falado, entre a letra e o significante. Neste contexto, "é a letra como tal que dá apoio ao significante" (idem), e a consequência deste privilégio (do escrito em detrimento do falado) é que ela:

“(...) é promovida, a partir daí, como um referente tão essencial quanto qualquer outra coisa, e isso modifica o estatuto do sujeito. O fato de ele se apoiar num céu constelado, e não apenas no traço unário, para sua identificação fundamental, explica que ele não possa apoiar-se senão no Tu, isto é, em todas as formas gramaticais cujo enunciado mais ínfimo é variado pelas leis de polidez que ele implica em seu significado. (idem)

Com a noção de traço, Lacan designa um modo de relação entre o eu e o objeto: o eu se liga ao objeto, tomando-lhe emprestado apenas um traço isolado, um único traço - einziger Zug (FREUD, 1921/1976, p.135). Na base da constituição do Ideal do Eu, este traço, traduzido como unário, coloca em jogo o significante como tal, fazendo vigorar a pura diferença. Se, com Saussure, a língua é um sistema de diferenças, Lacan (1961-1962) não deixa de se referir a ele quando, referindo-se à identificação ao traço, menciona a lógica binária em seu jogo com os sinais $(+)$ e $(-)$, o caçador contando os entalhes, a arte rupestre, a marca, o nome próprio.

Se não deixa de ocorrer que o ponto de referência do sujeito ocidental seja a unaridade da identificação - e isso, mesmo que o traço aglutine símbolos de identificação múltiplos — , é exatamente aí que o sujeito japonês se particulariza, uma vez que, para sua constituição, ele se apoia não apenas na identificação ao traço unário, mas em uma constelação de traços, em um "céu constelado" (LACAN, 1971/2003, p.24). Haver apoio em demasia é o mesmo que não haver apoio algum, ou seja, o que ocorre nesse caso é que a identificação fundamental sofre "uma pulverização” (MILLER, 1988, p.99) e isso leva o sujeito japonês a se apoiar nas variações das leis de polidez para sua identificação.

Lacan diz ser possível localizar a estrutura de ficção da verdade nos graus de cortesia que marcam as relações entre os japoneses, levando-nos a perceber que as boas maneiras são artifícios que nos dizem algo sobre a verdade japonesa. Assim, por meio desses artifícios de polidez - que jogam com as diferenças sociais - o sujeito mostra estar sob o efeito da lógica simbólica, ou seja, também 
para ele a língua se organiza como um sistema de diferenças (idem). No entanto, além desse apoio encontrado nos cerimoniais, no jogo com as aparências, com os semblantes, o sujeito japonês encontra na escritura uma outra possibilidade de ir além dos impasses aos quais ele chega pelas especificidades da sua língua.

Referindo-se ao Império dos signos, o psicanalista destaca o fato de Roland Barthes (1970) transmitir aí “o sentimento inebriado de que, com todas as suas boas maneiras, o sujeito japonês não dissimula nada” (LACAN, 1971/2003, p.24-25). No entanto, para ele o que há aí é um império dos semblantes, um império das aparências! Sendo assim, o suposto não dissimular nada leva Lacan a evidenciar que o sujeito japonês não teria nada do que se defender através do recalque (isto é, tornando-o inconsciente), uma vez que, pelas vicissitudes de sua língua, ao esbarrar em um limite ou em uma impossibilidade no registro do falado - no indizível, por exemplo —, ele simplesmente mudaria de registro, ou seja, se satisfaria com o exercício da escritura.

Sabe-se que a língua japonesa existia como língua falada antes da importação dos ideogramas chineses, de modo que existe a escrita chinesa antiga (on-yomi) e a leitura dela feita pelos japoneses (kun-yomi). O termo yomi designa leitura; a leitura on de um caractere chinês relaciona-se com a sua língua de origem, portanto ela não tem nenhuma significação em japonês. Já a leitura kun faz uma tradução do caractere chinês para a língua japonesa, tradução historicamente fixada e que traz o campo da significação. Em outros termos, a leitura on-yomi provém da cifração e é da ordem do Um, enquanto a leitura kun-yomi, além de ser decifrativa, se endereça ao Outro (OGASAWARA, 1998, p.66). A consequência disso pode ser formulada em termos simples: o sujeito japonês escreve uma coisa e fala outra. "Comparando ao inglês e ao latim, é como se ele escrevesse aqua (em latim) e lesse water (em inglês)" (GARCIA \& GONTIJO, 1989, p.30). Nesse sentido, o japonês é uma língua habitada por um constante movimento de tradução. Tudo o que é dito na conversação japonesa poderia ser lido por um recitante, afirma Lacan, concluindo, ironicamente, que se o Japão é o lugar onde o mais natural é se sustentar de um intérprete, isso ocorre precisamente "pelo fato de que ele não necessita interpretação. É a tradução perpétua feita linguagem”. Daí a sua conclusão sobre o Japão como o país do interprête, do "interpréstimo" (LACAN, 1971/2003, p.25).

\section{O MOVIMENTO CONSTELAR NAS ARTES LITERÁRIAS E PLÁSTICÁS}

Se o pensamento ocidental está construído segundo uma visão aristotélica, fundada na gramática grega e na estrutura linguística sujeito-predicado, isso não ocorre na lógica e linguagem chinesas, na medida em que elas evitam a dicotomia sujeito-predicado (RUESCH \& KEES, 1956/1975). Assim, ao se abrir a um método ideogrâmico de composição e tentar ultrapassar os obstáculos 
do ordenamento lógico-discursivo (tal como faz a linguagem matemática, por exemplo) a literatura aproximar-se-á do analógico e tentará criar, com o sistema fonético, isto é, com dígitos e letras, uma área linguística não discursiva, não verbal (CAMPOS \& PIGNATARI \& CAMPOS, 1975, p.82).

Surge assim um novo conceito de composição, ${ }^{2}$ uma nova teoria da forma na qual as noções de verso, silogismo, princípio, meio, fim etc., cederão seu lugar para uma organização poético-ideogramática na qual, ao invés do "analíticodiscursivo”, predominará o “sintético-ideogramático” (idem, p.25). Nesse contexto, interessará distinguir a comunicação verbal e a não verbal. Se a primeira está fundada em uma codificação de informações de tipo digital, cujos exemplos maiores são as combinações de letras e números tais como no alfabeto fonético e no sistema numérico, na segunda prevalece uma codificação analógica, na qual "várias espécies de ações, quadros ou objetos materiais representam análogos tipos de denotação” (RUESCH \& KEES' 1956/1975, p.82). Portanto, fica sugerido que, em termos de linguagem, 'digital' contrapõe-se à 'analógica', 'discursiva' à 'não discursiva'. Uma vez que a linguagem discursiva se funda na lógica e no seu conjunto de regras artificiais, ela dispensa as codificações analógicas. Esse jogo mostra-se nos exemplos que se seguem.

\section{Mallarmé: uma crise de verso e um lance de dados}

As vanguardas modernistas surgiram de uma crise na qual "o poeta cedeu a iniciativa às palavras" e elas se iluminaram de reflexos recíprocos, prescindindo de seu estilo, de seu sopro lírico e do seu entusiasmo pela frase (MALLARMÉ, 1895/2003, p.211). Os mosaicos tipográficos e eletrônicos do mundo moderno favoreceram o surgimento dessa crise e levaram o poeta a indagar sobre a sua possibilidade de criação. Assim, a leitura de simultaneidades, imposta pelos cartazes, slogans, manchetes, bem como de instantâneos em movimento — anúncios luminosos, histórias em quadrinhos etc. —- fez surgir uma crise na poesia subjetiva e de expressão e sinalizou a necessidade de uma comunicação rápida dos objetos culturais. O poema que nasce nesse momento, objeto concreto, está em relação com a fisiognomia industrial de sua época; "literatura industrial”, "produto tipo e não típico", ele acompanha o sentido da civilização progressivamente técnica (CAMPOS \& PIGNATARI \& CAMPOS, 1975, p.139).

Com Stephane Mallarmé (1842-1898), o poético abriu-se à não-linearidade, à estética do fragmentário e do prisma, e elas passaram a povoar o mundo literário da primeira metade do século XX. Nesse sentido, o acontecimento maior

\footnotetext{
2 Augusto de Campos menciona "as subdivisões prismáticas da Ideia" (Mallarmé), o método ideogrâmico (Erza Pound), a apresentação "verbivocovisual” (Joyce) e a mímica verbal de Cummings.
} 
foi a criação do poema “Un coup de dés jamais n’abolira le hasard” [Um lance de dados jamais abolirá o acaso]. Ao prefaciá-lo, Mallarmé indica que esse poema é uma sinfonia tipográfica que se desenvolve em "retrações, prolongamentos, fugas" e que resulta, para quem queira ler em voz alta, em uma partitura. Nela o relato é evitado e "a ficção, se ela se assoma, se dissipa, rapidamente, conforme a mobilidade do escrito” (MALLARMÉ, 1897/2003, p.391-392). A página, simultaneamente disposta, desdobrada, mostra caracteres diversificados e eles regulam a emissão oral e a disposição dos temas principais, secundários e adjacentes. Uma partitura, permeada de silêncios, separa grupos de palavras ou palavras entre si; movimento escandido, acelerado, delongado, que força um espaçamento da leitura (idem).

Precursor do "movimento constelar", o poema "Um lance de dados”, publicado em 1897, subverteu o campo poético e inaugurou um novo espaço no qual a língua surge como "um sistema de relações espaciais infinitamente complexas" (BLANCHOT, 1984, p.247). Desse modo, a modernidade nascente se viu diante de uma constelação de letras lançadas sobre uma página em branco, letras que restavam ali como:

\section{(...) Uma constelação}

fria de olvido e dessuetude não tanto

que não enumere

sobre alguma superfície vacante e superior

o choque sucessivo

sideralmente

de um cálculo total em formação

vigiando

duvidando

rolando

brilhando e meditando

antes de se deter

em algum ponto que o sagre

Todo pensamento emite um Lance de Dados

(MALLARMÉ, 1897/2003, p.387)

Subvertidos pelo lançar dos dados, os conceitos poéticos de tempo e espaço deram lugar a "uma valorização gráfica da página, que se transformou em um 
enorme palco onde a linguagem encena a sua própria construção (ou destruição)" (MACIEL, 1999, p.153-154). Apresenta-se aí um jogo de racionalidade e acaso no qual a contingência não é abolida e o surgimento da constelação envolve o poema como uma forma nova e opera como "uma disciplina controladora do acaso" (CAMPOS \& PIGNATARI \& CAMPOS, 1975, p.85). Do ponto de vista de uma teoria da composição, conclui-se que o acaso torna-se parte integrante do processo de criação. Se ele não é vencido, “é pelo menos atraído ao rigor da palavra e elevado à firme figura de uma forma onde ele se encerra”: a forma constelar (BLANCHOT, 1984, p.245).

\section{OS CALIGRAMAS DE G. APOLLINAIRE}

\section{E AS CINTILAÇÕES DE E.E. CUMMINGS}

“(...) é preciso que nossa inteligência se habitue a compreender sintético-ideograficamente em lugar de analítico-discursivamente" (APOLLINAIRE apud CAMPOS \& PIGNATARI \& CAMPOS, 1975, p.20-22). Com tal proposta, Guilhaume Apollinaire (1880-1918) apresenta o espírito com o qual produziu os seus Calligrammes, uma série de poemas criada entre 1912-1918. Diante dos seus poemas, o escritor insiste em que o laço textual "não é mais o da lógica gramatical, mas o de uma lógica ideográfica que chega a uma ordem de disposição espacial totalmente contrária à da justaposição discursiva" (idem). No caligrama "La petite auto", o poeta moderno circula com seu auto, os recursos gráficos e tipográficos. Um uso inusitado do espaço configura o poema de modo constelar:

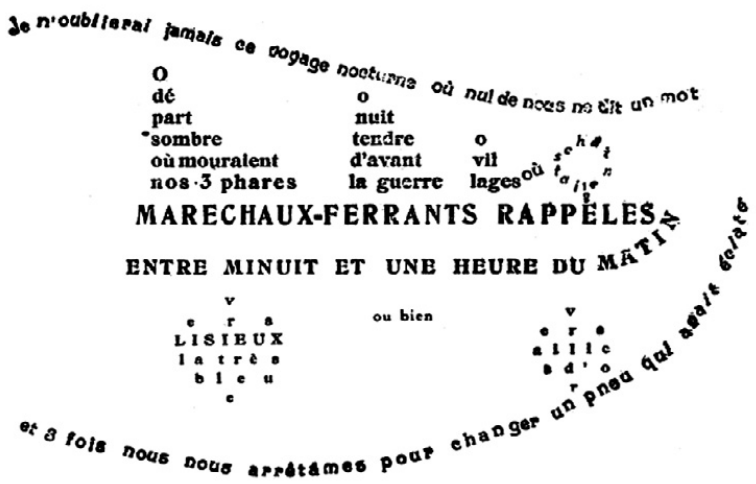

Todavia, o objetivo declarado de que seus caligramas apresentassem um conjunto pictural em relação ao tema tratado, atingindo "o ideograma quase perfeito”, fez com que o ideograma poético fosse condenado “à mera representação figurativa do tema (...) a uma relação fisionômica entre as palavras e o objeto por elas representado" (idem, p.21). 
De modo menos pueril, e.e. Cummings (1894-1962) fez variações com a forma, pontuação, soletramento e sintaxe, e deixou de lado as técnicas e as estruturas tradicionais para inventar meios de expressão poética bastante pessoais. Se, para obter "uma equivalência fisiognômica do brilho estelar", Apollinaire colocaria as palavras em forma de estrelas, Cummings trabalha com as palavras, bright, star, big, near, calm, holy, deep, alone, yes, who, para compor, com "a sua justaposição, livre de conectivos, o ideograma do impacto de uma noite estrelada” (idem, p.24). No seu poema “bright”, por meio de pulverizações e com sutileza, ele produz cintilações ao fazer uma letra maiúscula se movimentar dentro das palavras ou, então, ao usar pontos de interrogação em lugar de algumas letras das palavras star e bright (idem). Temos:

\author{
brIght \\ brIght s??? big \\ (soft) \\ Soft near calm \\ (Bright) \\ calm st?? holy \\ (soft briGht deep) \\ yeS near sta? Calm star big yEs \\ alone \\ (wHo \\ Yes \\ near deep wHo big alone soft near \\ deep calm deep \\ ???Ht ?????T \\ (Who (holy alone)holy (alone holy) alone
}

(CUMMINGS, 1978, s.p.)

O próprio Cummings observou que seria impossível traduzir a sua typewriter language para uma linotype-ese. Ao comentar os star poems do poeta norte-americano, Richard S. Kennedy (1978) observa que, através deles, Cummings não deixa de aludir à estrela de Belém e ao hino religioso "Silent night, holy night. /All is calm, all is bright" e, isso, para alegria de seu pai, um reverendo cristão que escolhera a estrela de Belém como seu principal símbolo. 


\section{Ezra Pound e o método ideogramático de composição}

Esse modo de agrupamento denominado “constelação" pode ser associado ao que Erza Pound fez surgir a partir da poesia chinesa: o princípio de condensação e o método ideogrâmico de compor, isto é, “justaposição direta de elementos em conjuntos geradores de relações novas” (idem, p.99). Esse poeta americano (1885-1972) foi precursor no estabelecimento de uma aproximação da poesia e de seus métodos de composição com o método ideogrâmico chinês (CAMPOS, 1993). Embora Apollinaire lhe seja anterior, ele acabou por fazer disso um uso pouco sutil.

No horizonte das contribuições de Pound, encontram-se ressonâncias do ensaio de Ernest Fenollosa "The Chinese written character as a medium for poetry" (FENOLLOSA, 2000, p.109-128), segundo o qual a linguagem escrita chinesa absorveu a substância poética da Natureza e, por meio da sua visibilidade pictórica, conservou na poesia um vigor e uma vivacidade maiores do que aqueles obtidos por qualquer língua fonética. À medida que a língua chinesa desconhece naturalmente a gramática, o filósofo e sinólogo, cujo artigo Pound publicou em 1919, assinala que a leitura da poesia chinesa nos impõe o abandono das categorias gramaticais, de modo que o encanto da impressão direta — "esplêndido lampejo de poesia concreta” — , ilumine zonas onde o intelecto pode apenas tatear. Nesse sentido, o poeta é convocado a fazer da língua um uso tão rico e concreto, quanto a própria Natureza: “o modelo de sentença, na Natureza, é um fulgor de relâmpago. Passa entre dois termos, uma nuvem e a terra" (idem, p.118).

Essa consciência crítica seletiva, a partir da qual o poema encontra um mínimo de organização construtiva, será rejeitada pelos futuristas e dadaístas na medida em que eles querem deixar ao leitor o máximo de liberdade para estabelecer as suas próprias associações. O maior expoente desse livre-associacionismo, que desemboca no automatismo psíquico, será o movimento surrealista. Em vista disso, não é difícil perceber que o poema concreto se distingue radicalmente da escrita automática, na qual predomina o reino do paradoxo e do nonsense, experiências que desembocam em um "irracionalismo subjetivista” (CAMPOS \& PIGNATARI \& CAMPOS, 1975, p.77-78).

\section{A poesia concreta}

O “movimento constelar”, que floresceu na primeira metade do século XX, ressurgiu entre os anos 1952-1970 com da poesia concreta. Nela, o poeta inspirado e/ou maldito dá lugar ao "poeta factivo" e o poema se transforma em "um objeto útil, consumível, um objeto plástico” (idem, p.25). Ataca-se a organização convencional do poema - cuja unidade formal é o verso — , de modo que "o núcleo poético é posto em evidência não mais pelo encadeamento sucessivo e 
linear de versos, mas por um sistema de relações e equilíbrios entre quaisquer partes do poema” (idem, p.44-45). Nessa “poesia-sem-verso” (idem, p.58), ganha importância um campo relacional de funções gráfico-fonéticas e uma justaposição de palavras que levam o leitor a uma experiência "verbivocovisual” (idem, p.45), para usar um termo de James Joyce. Também denominado ideograma, o poema concreto introduz o espaço como elemento fundamental à estrutura poética: “o ritmo tradicional, linear, é destruído” (idem, p.62).

Essa poesia entende por forma "a maneira pela qual o escritor manipula o material para produzir o efeito artístico [...] Se a prosa é o império dos signos [linguísticos], a poesia ficará ao lado da pintura, da escultura e da música” (idem, p.49-50). No entender de Augusto de Campos, ao tratar a palavra como coisa, o poema concreto se propõe a uma associação de formas, e não de ideias. Décio Pignatari mostra, no poema “Terra”, um predomínio da forma orgânica de composição espacial. No seu entender, o isomorfismo tende à fisiognomia e a um movimento imitativo do real, entretanto o poema tenderá a um puro movimento estrutural e dinâmico, momento no qual a forma geométrica ou matemática é preponderante (idem, p.89).

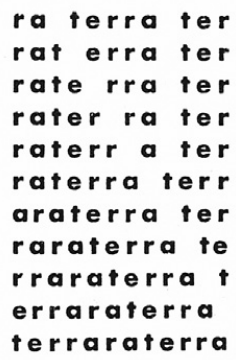

(CAMPOS \& PIGNATARI \& CAMPOS, 1975, p.75)

Tal como na matemática, o poema concreto possui "um instrumento de controle que evidencia e elimina os elementos que entrem em contradição com sua estrutura rigorosa” (idem). Nesse sentido, a palavra terra é o núcleo gerador do conjunto racional que é o poema acima: terra - erra - ara terra - rara terra - erra ara terra - terra ara terra; uma locução terra a terra acompanha o "coro fonético virtual”. Ainda de acordo com seu criador, o poema “Terra” gera-se a si próprio e se autocorrige. Ele opera uma passagem do fisionômico (sulcos brancos $=$ sulcos numa terra arada) ao isomórfico (estrutura visual = estrutura verbal) (idem, p.77-79).

\section{As constelações de Joan Miró e o surrealismo de André Breton}

Em que pese a crítica dos concretistas, nessa abordagem panorâmica da literatura constelar na primeira metade do século XX as constelações surrealistas têm 
sua importância e interesse na medida em que, em sua conexão com a pintura, ultrapassam a dimensão puramente tipográfica (industrial) do poema feito à máquina e resgatam algo do caráter caligráfico presente no ideograma. Assim, surge uma série de 22 guaches intitulada Constelações, produzida entre 1940-1941 por Joan Miró (1893-1983). Ele nos comunica ter acreditado, por volta dos anos 1940, não haver qualquer esperança no porvir, portanto pensara em exprimir essa sensação “desenhando emblemas e formas como se as fizesse na areia antes que as ondas avançassem, ou arabescos no ar como se produzidos pelo fumo do cigarro, tal como se evolassem para as estrelas fugindo a um mundo de apodrecimento e fedor" (PENROSE, 1983, p.98-99).

Depois de ter dito não fazer nenhuma diferença entre a pintura e a poesia, o artista espanhol começou a nomear as telas em linguagem poética. Assim, os títulos da série Constelações constituem, eles próprios, um poema. Entre a abertura com o Nascer do Sol e a finalização com A passagem do pássaro divino, temos $O$ canto do rouxinol à meia-noite e a chuva matinal, O 13 a escada que roçou o firmamento, Mulheres junto a um lago cuja superfície se tornou iridiscente pela passagem de um cisne, Personagens na noite guiados pelos traços fosforescentes dos caracóis, O belo pássaro decifrando o desconhecido para o casal amoroso, Mulher prisioneira de um voo de ave etc. Nos termos de um crítico de arte, se os títulos não deixam de indicar esperanças de salvação, “o guia mais antigo e infalível Miró achou-o definitivamente nas próprias constelações” (idem, p.102-103).

Com a escritura automática de suas telas, o artista plástico se incluiu entre os poetas, uma vez que parece ter reconhecido a necessidade de "ultrapassar a coisa plástica para atingir a poesia” (PEDROSA, 1976, p.44). Todavia, essa poética, ele próprio a aproximou àquela dos povos primitivos e dos japoneses, uma vez que eles “reduzem tudo o que está na natureza e no cosmo a signos” (idem, p.45-48). Esses signos pertenceriam a um tipo de "linguagem secreta", tal como sugere a tradição estética dos calígrafos chineses e japoneses. Nesse sentido, com os seus “arabescos constelares", ele se aproxima do gesto do calígrafo para o qual "tudo repousa sobre a aventura de uma única linha em cada quadro" (idem).

Em face das Constelações de Miró, André Breton (1896-1966) tentou recriar, com palavras, aquilo que a pintura fez com imagens formais. Diante da série de telas, ele produziu 22 pequenos escritos automáticos inseridos no verso de cada uma das telas. Para esclarecer a intenção do pintor, ele empregou "a phrase-fusée, jorrando em feixe cintilante e prolongado, ou estriando com um breve clarão na obscuridade da incompreensão” (ALEXANDRIAN, s/d, p.146-147). Nesses escritos, "a frase distendida pode terminar o texto com uma conclusão fulgurante, ou ser colocada no seu início; mais frequentemente, no entanto, ela resplandece no seu interior, irradiando o conjunto das informações precisas que ele reuniu sobre o artista em questão” (idem). É o que se mostra a seguir: 


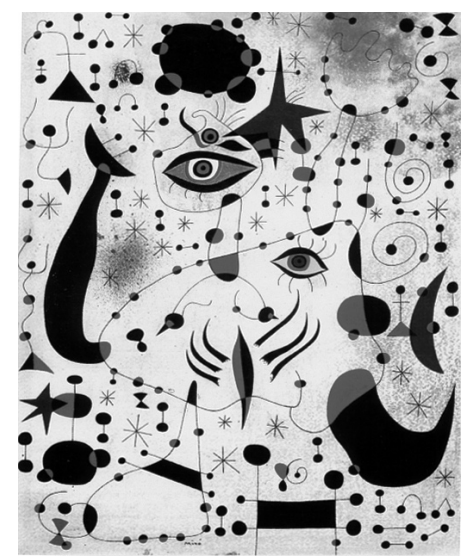

(Constelações e cifras apaixonadas por uma mulher [Miró, 1941])

"Ao glóbulo de vida toda a sorte e por isso ele aglomera-se em si mesmo tantas vezes quanto a gota de chuva sobre a folha e a vidraça, segundo os traçados apenas decididos e já desaparecidos cujo segredo ela guarda e isso em tantos sentidos quanto os indicados pelos raios de sol. É como as pérolas dessas caixinhas redondas da infância brinquedo que não se vê mais que prendiam a atenção ao preço de uma longa paciência até que se pontuasse até ao último alvéolo uma boca esboçando um sorriso. A cabeça de Ogmius penteada do javali soa sempre clara através da chuvarada: para sempre ela oferece-nos um rosto cunhado do mesmo cunho que os céus. Ao centro, a beleza original, balbuciante de vogais, servida de um supremo dedilhado pelos números.” (BRETON, 1958/1968, p.165)

No seu escrito, Breton se refere a Ogmius, o deus gaulês da eloquência e ao seu jogo secreto com as letras e números. Na medida que, nas artes plásticas gaulesas, o discurso eloquente de Ogmius foi representado por uma fina corrente dourada ligando a ponta de sua língua às orelhas de um grupo de seguidores, isso não deixa de sugerir que a constelação surrealista estaria atravessada pela relação mestre-discípulo. Todavia, à diferença de uma figuração heliocêntrica, o funcionamento constelar distende os elementos não apenas nas frases, como também na tela; indica-se assim a potência e os segredos da criação artística: o objeto criado "não será germinador senão à medida que fôr, ele-próprio, língua múltipla, rede de sentidos entrelaçados" (RAILLARD, 1976, p.56-58).

\section{O mosaico benjaminiano}

Se até agora o acento constelar incidiu sobre o espaço poético e pictórico, cabe lembrar que ele incidiu também no campo da prosa, conferindo-lhe um estilo de mosaico. Contemporâneo do movimento surrealista, ao qual dedicou um 
ensaio elogioso, o filósofo e crítico de arte Walter Benjamin (1892-1940) chegou a aproximar o espaço descrito pela lírica surrealista — o pequeno mundo parisiense - , e o cosmo, grande mundo no qual "também existem encruzilhadas, nas quais sinais fantasmagóricos cintilam através do tráfico” (BENJAMIN, 1994, p.27). Orientar-se por cintilações não deixa de ser uma referência às constelações, figura recorrente dos primeiros ao último texto do original ensaísta. Já em Origem do drama barroco alemão (1925), ele sugere que "as ideias se relacionam com as coisas como as constelações com as estrelas"; as ideias seriam constelações intemporais que apreendem os elementos como pontos luminosos nessas constelações; elas dividem e salvam os fenômenos, levando-os a participarem do Ser das ideias (BENJAMIN, s/d, p.56-57). Tal como cada estrela localiza-se em um ponto em relação ao traçado do conjunto, a constelação apresenta o ponto em que "o extremo se encontra com o extremo" (idem).

Mais além do uso puramente metafórico do termo, os escritos benjaminianos são, eles próprios, construídos de modo constelar. À diferença das experimentações formais dos poetas, a linearidade gráfica do texto é mantida, todavia a sequência início-meio-fim é rompida e o leitor, "bruscamente mergulhado in medias res, encontra um 'mosaico’ de reflexões cuja ligação não é feita através de uma concatenação textual-linear, mas através de uma rede de conexões intra ou intertextuais" (OTTE \& VOLPE). O caráter constelar manifesta-se pelo predomínio do fragmentário sobre o sistemático, pela retomada constante dos mesmos temas, nos seus vários estratos de significação, i.é., nos seus extremos, e pelas rupturas ou passagens bruscas de um tópico para outro.

“Benjamin quer ser lido como um mosaico, mas até certo ponto esse mosaico tem de ser construído pelo leitor. Nem sempre as peças estão ordenadas. O livro tem grandes articulações, dentro de cada capítulo, mas não existem parágrafos dentro de cada articulação. Cabe ao leitor separar e juntar os fragmentos" (ROANET, s/d, p.22-23). A técnica da montagem, que atingirá seu uso máximo no livro das Passagens, apresenta-se desde os primeiros escritos por meio do mosaico de citações: "estilhaços de ideias, arrancadas do seu contexto original, e que precisam renascer num novo universo relacional, contribuindo para a formação de um novo todo”, comenta Rouanet (idem). Para tal, a implicação do leitor é fundamental, uma vez que o próprio da leitura do texto constelar é a liberdade deixada ao leitor para estabelecer ligações entre as partes dispersas (OTTE \& VOLPE).

No seu último texto, “Sobre o conceito da história” (1940), Benjamin apresenta uma espécie de procedimento metodológico que "faz explodir o continuum da história”: "pensar não inclui apenas o movimento das ideias, mas também a sua imobilização. Quando o pensamento para, bruscamente, numa configuração (Konstellation) saturada de tensões, ele lhes comunica um choque, através 
do qual essa configuração (Konstellation) se cristaliza enquanto mônada” (tese 17) (BENJAMIN, 1994, p.230-231).

Ao incidir no universo textual, a ruptura com a linha do tempo homogêneo e vazio (essa que lê a história de modo progressivo) produz uma verticalização. A destruição da linearidade, cujo resultado será exatamente o constelar, se processa por diversos modos de interrupção: a imobilização ("um tempo saturado de “agoras”'); a cristalização (uma fixação); o salto (rupturas); o relâmpago (imagem por meio da qual o passado relampeja sobre o presente, invertendo a flecha do tempo); o choque (que surge quando se colocam elementos heterogêneos lado a lado). Se o resultado imediato da deslinearização é a produção de fragmentos, ruínas, detritos que perdem o seu sinal negativo quando tratados como 'vestígios' (OTTE \& VOLPE), com o choque o agrupamento constelar transforma-se em mônada, isto é, uma forma autárquica que contém a imagem de todas as outras formas. Com a leitura monadológica, Benjamin faz falar o particular, até que, nessa fala, se revelem as suas relações com o todo (ROANET, s/d, p.20), concebido na forma de um mosaico.

Se a imagem do passado relampeja sobre o presente, iluminando-o e abrindo o "espaço da história” (como a madeleine de Proust), no universo escritural a inclusão de uma citação, por exemplo, pode interromper o fluxo da cadeia de ideias, deslinearizando o texto e gerando um outro “espaço literário”. Nele, os próprios fatos, em um dado momento, revelam suas afinidades mútuas e se reúnem em constelação (OTTE, 1996, p.211; p.223).

\section{RETORNO AO CAMPO DA PSICANÁLISE: DA CONSTELAÇÃO AOS ENXAMES}

Uma vez feito um sobrevôo sobre o constelar no campo das artes, é interessante verificar como esse modo de funcionamento incide sobre a teoria e a clínica psicanalíticas a partir dos anos 1970. Se na perspectiva linear há um movimento associativo, conectivo, articulativo $(\mathrm{S} 1 \longrightarrow \mathrm{S} 2)$, na outra, constelar, ocorre um movimento de dissociação e ele introduz uma desconexão, uma desarticulação entre os significantes (S1//S2). A ruptura da linearidade da cadeia significante não deixa de ter consequência sobre a noção de representação e sobre o estatuto do sujeito (MILLER, 1987/1999). Tal como dito antes, de uma perspectiva para outra o significante se solta e se transforma em insígnia (idem, p.344). Desconectado da cadeia, esse significante solto ganha estatuto de letra, já que uma letra é essa unidade no campo da linguagem que não se refere a outras: "se o significante se define e se agrupa por sua diferença, a letra não é diferencial e, além disso, pode ser captada fora dos efeitos de sentido. Por letra entende-se, portanto, o isso fala, o isso, que subsiste como tal" (idem, p.348-349). Isso fala, isso goza, e nada sabe (LACAN, 1972/1973, p.142). Assim, a insígnia é signo, signo de gozo. 
Com a introdução da noção de letra nos anos 1970, a teoria lacaniana afasta-se do significante saussuriano fundado sobre uma prevalência da dimensão falada sobre a dimensão escrita da língua. À medida que deixa para trás a hegemonia da linguística estrutural em sua dimensão significante e representativa, Lacan torna evidente que o fenômeno essencial da língua não é o sentido, mas o gozo: é a pulsão, e não a significação, que move o ser falante. Surge assim a noção de alíngua (lalangue), concebida como uma espécie de lalação na qual o uso da língua não deixa de comportar satisfação pulsional.

Depois de ter usado o termo "constelação de insígnias” referindo-se aos traços do Ideal do Eu em 1958 e de ter tratado o estatuto constelar do sujeito japonês, devido às especificidades de sua língua, em 1971, Lacan retoma essas questões sob novos termos. Assim, aos traços do I(A) ele se refere através do termo 'Significante Mestre' (S1) e às questões relativas ao constelar sob o termo 'enxame'. Desse modo, um giro nos transporta do significante à letra e ao enxame de significantes mestres: S1, S1, S1, S1... Esse um (S1), esse enxame ${ }^{3}$ - termo que a partir daí substitui-se àquele de constelação — , Lacan vai encarná-lo na alíngua (lalangue), mostrando que esses uns restam indecisos entre o fonema, a palavra, a frase, o pensamento.

À medida que o Um do traço é pluralizado, temos um enxame (essaim) de traços, um enxame de S1s: S1(S1[S1\{S1 $\rightarrow \mathrm{S} 2\}])$, "um enxame que zumbe" (idem, p.196-197). Logo, se nas primeiras formulações de Lacan o significante representa o sujeito para um outro significante, com a noção de enxame essa dimensão representativa fica em questão: a relação de um significante a outro é simétrica, antissimétrica, transitiva ou o sujeito se transfere do S2 a um S3 e assim por diante? Se não é mais a noção (ou mesmo a nomeação) de (uma) 'constelação' que faz a amarração entre os vários pontos desconhecidos uns dos outros, como esses uns se agrupam? Tomando, então, um pedaço de barbante, o psicanalista faz uma rodinha e interroga a sua possibilidade de fazer nó com uma outra rodinha de barbante.

Com as formulações produzidas em meados dos anos 1970, Lacan introduz outra concepção do inconsciente: se a articulação entre um significante e outro $(\mathrm{S} 1 \longrightarrow \mathrm{S} 2)$ permite que o sujeito se represente e que o gozo se localize — conforme a formalização do inconsciente pelo Discurso do Mestre - , nessa nova concepção só haverá Uns no inconsciente (S1 S1 S1 S1 S1), Uns suscetíveis de se escreverem com uma letra. Assim, temos uma apresentação do "inconsciente discursivo" (captado na linguagem falada), e outra, de um "inconsciente escritural” (escriturado, letrificado), que se sustenta ali onde só há S1, letra que se repete (MILLER, 1987/1999, p.347-349).

\footnotetext{
${ }^{3}$ Em francês o termo 'enxame', essaim, é homófono a S1.
} 
Essa concepção do inconsciente constituído de traços ímpares, memórias de gozo, ${ }^{4}$ levará Lacan a fazer outra leitura do sintoma. Se o sintoma é aquilo que não cessa de se escrever, essa modalidade necessária de escrita leva o psicanalista a constatar que a escritura pode operar como um modo de amarração do sujeito. Nesse sentido, não parece despropositado dizer que o sujeito constelar, com o qual ele esbarrou por meio da língua japonesa, lhe abriu passagem para as suas últimas elaborações, nas quais a cadeia significante e o enxame de letras desembocarão na escritura topológica do nó de Borromeu. ${ }^{5}$

\section{CONCLUSÃO}

Lacan afirma que, por estar escrito, o sintoma pode ser lido, todavia se não houver alguém para lê-lo ele permanecerá "irredutível em seu absoluto de significante, por tantos séculos quantos ficaram os hieróglifos no deserto” (1957/1998, p.447), o silêncio das estrelas ou dos espaços infinitos. Talvez por isso, artistas e escritores sempre se movimentem no sentido de dar a ver e de dar a ler as suas invenções sintomáticas.

Não deixa de ser interessante constatar que a hegemonia do estruturalismo no campo das ciências humanas, incluindo-se aí a psicanálise, manteve em suas margens até o início dos anos 1970 (precisamente quando ele declina no campo das artes) um movimento bastante intenso no horizonte da subjetividade criadora dessa época, o movimento constelar, e isso, provavelmente pelo fato de ele colocar em questão os pressupostos fundamentais de uma concepção de língua fundada na linearidade significante. Se o inconsciente se estrutura como uma linguagem, isso só se sustenta na medida que se pensa a linguagem de modo saussuriano. Assim, o movimento constelar propõe à psicanálise estruturalista questões do tipo: como conceber o inconsciente em uma língua não fonética, em língua japonesa, por exemplo?

Lacan comenta que, tal como é feita a sua língua, um japonês só precisa de uma caneta, um stylo, quando um ocidental precisa construir um estilo (LACAN, 1972/2003, p.500). Ou seja, insatisfeito com o falado, o sujeito japonês oscila para a satisfação trazida pelo escrito e se poupa de lidar com os limites do dizível (S de A barrado) e do trabalho de criar um estilo, isto é, de se haver com o objeto. Assim, o psicanalista conclui que, tal como está estruturada, essa língua veda as formações do inconsciente e isso faz com que o sujeito seja inanalisável

\footnotetext{
${ }^{4}$ Ressalta-se aí a afinidade da marca com o gozo. Nos termos de Lacan: "A repetição é uma denotação precisa de um traço, [...] como idêntico ao traço unário, ao pequeno bastão, ao elemento da escrita, um traço na medida que comemora uma irrupção de gozo" (LACAN, 1992, p.73).

${ }^{5}$ Embora fuja ao alcance deste trabalho examiná-lo, interessa lembrar que o enxame é considerado o grupo fundamental do nó Borromeu. Cf. Vappereau, 1985.
} 
em língua japonesa, uma vez que ele se subtrai "aos artifícios do inconsciente, que não o atingem, por ali se fechar" (LACAN, 1964/1985, p.265).

Ao final de seu ensino, Lacan parece interessar-se pelo que toca os limites da psicanálise, “como se avaliasse as condições da psicanálise a partir da inanalisabilidade". ${ }^{6}$ No entanto, o sintoma e suas novas formas insistem e forçam o campo teórico e clínico da psicanálise. Em vista disso cabe notar que, ainda sobre a língua japonesa, Lacan (1972/2003, p.499) afirmou: "ninguém que habite essa língua precisa ser psicanalisado, a não ser para regularizar suas relações com as máquinas de moedas..."

Recebido em 1/10/2007. Aprovado em 5/3/2008.

\section{REFERÊNCIAS}

ALEXANDRIAN, S. (s/d) André Breton par lui-même. Paris: Seuil.

APOLLINAIRE, G. "La petite auto”. Calligrammes. Disponível em: www. ubu.com/historical/app/app2.html. Acesso em 15/4/2003.

BENJAMIN, W. (1994) Obras escolhidas, v.1. São Paulo: Brasiliense. (1925/ s/d) Origem do drama barroco alemão. São Paulo: Brasiliense. BLANCHOT, M. (1984) O livro por vir. Lisboa: Relógio d’Água Editores.

BRANCO, L.C. (2000) Os absolutamente sós, Lhansol, a letra, Lacan. Belo Horizonte: Autêntica.

BRETON, A. (1958/1968) Signe ascendant. Paris: Gallimard.

CAMPOS, A. \& PIGNATARI, Décio \& CAMPOS, H. (1975) Teoria da poesia concreta, Textos críticos e manifestos 1950-1960. 2 ed. São Paulo: Livraria Duas Cidades.

CAMPOS, A. (1993) Erza Pound. Poesia. São Paulo/Brasília: Hucitec/Universidade de Brasília.

CAMPOS, H. (Org.) (2000) Ideograma: Lógica, poesia, linguagem. 4 ed. São Paulo: Edusp.

CUMMINGS, e.e. (1978) No thanks. New York: Liveright.

FENOLLOSA, E. (2000) "Os caracteres da escrita chinesa como instrumento para a poesia”. in CAMPOS, H. Ideograma: Lógica, poesia, linguagem. São Paulo: Edusp.

FREUD, S. (1976) Edição standard brasileira das obras completas de Sigmund Freud: Imago Editora.

(1921) Psicologia de grupo e análise do ego”, v. XVIII, p.133-141.

GARCIA, C. \& GONTIJO, T. (1989) "Coisa de japonês". Isso. Despensa Freudiana. n. 01. Belo Horizonte.

LACAN, J. ( 1954-1955/1985) O Seminário, livro 2, O eu na teoria de Freud e na técnica da psicanálise. Rio de Janeiro: Jorge Zahar.

${ }^{6}$ Comentário feito por Ram Avraham Mandil. 
(1953/1980) O mito individual do neurótico. Lisboa: Assírio e Alvim.

(1957/1998) “A psicanálise e seu ensino”, in Escritos. Rio de Janeiro: Jorge Zahar.

(1958/1998) "Observação sobre o relatório de Daniel Lagache: Psicanálise e estrutura da personalidade”. In Escritos. Rio de Janeiro: Jorge Zahar.

(1959-1960/1988) O Seminário, Livro 7, A ética da psicanálise. Rio de Janeiro: Jorge Zahar.

(1960-1961/1992) O Seminário, Livro 8, A transferência. Rio de Janeiro: Jorge Zahar.

(1961-1962) O Seminário, Livro 9, A identificação. Inédito.

(1962-1963/2005) O Seminário, Livro 10, A angústia. Rio de Janeiro:

Jorge Zahar.

(1964/1985) O Seminário, Livro 11, Os quatro conceitos fundamentais da psicanálise.Rio de Janeiro: Jorge Zahar.

(1971/2003) "Lituraterre", in LACAN, J. Outros escritos. Rio de Janeiro: Jorge Zahar.

(1972/2003) "Aviso ao leitor japonês", in LACAN, J. Outros escritos. Rio de Janeiro: Jorge Zahar.

(1972-1973/1982) O Seminário, Livro 20. Mais, ainda. Rio de Janeiro:

Jorge Zahar.

(1992) Seminário, Livro 17, O avesso da psicanálise. Rio de Janeiro: Jorge Zahar Editor.

MALLARMÉ, S. (1895/2003) “Crise de vers”. Divagations. Oeuvres complètes, v. II. Édition présentée et annotée par Bertrand Marchal. Paris: Gallimard.

(1897/2003) "Observation relative au poème Un Coup de Dés jamais n'abolira le Hasard”. Oeuvres complètes, v. I. Édition présentée et annotée par Bertrand Marchal. Paris: Gallimard.

(1897/2003) "Un Coup de dés jamais n'abolira le hasard". Oeuvres complètes, Édition presentée et annotée par Bertrand Marchal. Paris: Gallimard.

MACIEL, M.E. (1999) Voo transverso. Rio de Janeiro: Sete Letras.

MILLER, J.-A. (1988) Lacan et la chose japonaise. Paris: Navarin.

(1987/1999) Los signos del goce. Los cursos psiconalíticos de Jacques-Alain Miller. Buenos Aires/Barcelona/México: Paidós.

OGASAWARA, S. (1998) “O japonês é analisável?”. Correio. n. 18/19. Belo Horizonte: Escola Brasileira de Psicanálise, p.64-70.

OTTE, G. (1996) “Rememoração e citação em Walter Benjamim”. Revista de Estudos de Literatura, v. 4, Belo Horizonte: Faculdade de Letras/ UFMG, p.211-223.

OTTE, G. \& VOLPE, M. L. (2003) “Um olhar constelar sobre o pensamento de Walter Benjamin”. Disponível em: http://sites.uol.com.br/georg. otte/publicacoes/Constelacao.htm. Acesso em 10/4/2003.

PEDROSA, M. (1976) “Miró parmi les poets". Opus International. n.58. Paris. s/p.

PENROSE, R. (1983) Miró. s/l: Editorial Verbo. 
KENNEDY, R. S. (1978) “Introduction”. No thanks. New York: Liveright. RAILlARD, G. (1976) “Comment André Breton s'est approprié les Constellations”. Opus International, n. 58. Paris, s/p.

ROANET, S.P. (s/d) "Apresentação”, in Origem do drama barroco alemão. São Paulo: Brasiliense.

ROSA VIEIRA, M. (2005) "Fernando Pessoa e Jacques Lacan: constelações, letra e livro”. Tese de Doutorado, Programa de Pós-graduação em Letras: Estudos Literários, Fale, Universidade Federal de Minas Gerais.

RUESCH, J. \& KEES, W. (1956/1975) Comunicação não verbal, in CAMPOS, H. PIGNATARI, D. \& CAMPOS, A. Teoria da poesia concreta , Textos críticos e manifestos 1950-1960. 2 ed. São Paulo: Livraria Duas Cidades. (Nota 13), p.82.

VAPPEREAU, Jean Michel. (1985) Essaim, le groupe fondamental du noeud. Paris: Point Hors Ligne.

Márcia Rosa

marcia.rosa@globo.com 